\title{
EN TORNO A LAS REDES \\ DE EMPRESA Y EL TERRITORIO
}

\section{Ignasi Brunet Icart y Angel Belzunegui Eraso \\ Universidad Rovira Virgili}

\begin{abstract}
RESUMEN
Este artículo analiza las implicaciones de la empresa con el territorio donde desarrolla sus actividades. La empresa no existe al margen de los procesos sociales, culturales, políticos y económicos del tejido social que la rodea. En este artículo se realiza un recorrido sobre la localización de las actividades productivas, la identificación de las economías dinámicas, tal como las denominó Marshall, y la formación de espacios territoriales, más o menos especializados, donde se han generado sinergias productivas estudiadas por economistas y sociólogos a lo largo de las últimas décadas. Se exponen más detenidamente la dinámica de los clusters, los distritos industriales, para acabar mencionando, también, algunos aspectos más relevantes de los mercados de trabajo locales.
\end{abstract}

En los últimos años se ha puesto de manifiesto la necesidad de mirar hacia el interior de la empresa para descubrir las ventajas competitivas que la diferencian de sus competidoras. Es por esto que ha irrumpido el enfoque de recursos y capacidades constituyendo un instrumento clave en la teoría de la estrategia como explicación de la consecución de la ventaja competitiva de las empresas.

Es un discurso que durante la década de los años noventa se ha abierto paso incidiendo en los factores internos estructurantes de la empresa y dejando de acentuar los factores más estructurales que se identifican con el entorno. Sin 
embargo, el territorio sigue requiriendo, desde nuestro punto de vista, un continuo estudio que ponga de manifiesto las transformaciones que afectan el asentamiento de las actividades productivas, los modelos de desarrollo económico local y la expansión y/o contracciones de los denominados mercados locales de trabajo.

La emergencia de zonas industriales en donde se concentran empresas especializadas en actividades complementarias ha generado una literatura que analiza las interdependencias organizativas presentes en un territorio determinado y que determinarían una serie de competencias distintivas claves que situarían a las empresas en situación de ventaja competitiva. La idea central es que la capacidad competitiva de una empresa no depende sólo de los recursos que ésta controla directamente (por ejemplo, de gran parte de los recursos internos), sino que también depende de los recursos y capacidades a los que tiene acceso dentro de su territorio cercano. Estos recursos son activados por el soporte de la red de relaciones entre empresas ${ }^{1}$ y responden, con frecuencia, a estrategias colectivas, donde los actores adquieren un protagonismo esencial en la propia transformación del sistema productivo en el entorno. Explotar o activar eficientemente los recursos compartidos que tienen un carácter público en el interior del territorio pero privado respecto a otros, justifica estrategias colectivas de diferenciación de la producción que constituyen una de las formas de organización flexible ajustadas a la demanda y adaptadas a los retos de la competencia global ${ }^{2}$.

En la formulación de Piore y Sabel (1990), tanto las redes organizativas japonesas como los denominados distritos industriales se encuentran entre las formas de especialización flexible, formas que plantean una segunda ruptura industrial respecto a la primera ruptura que conllevó la aparición de la producción en masa y su predominio en relación a la producción artesanal ${ }^{3}$. Castells (1997) distingue en el sistema de producción flexible una práctica de especialización flexible cuyo prototipo son los distritos industriales, y una práctica de producción flexible de alto nivel que combina la producción de alto volumen, que permite economías de escala con sistemas de producción personalizada y reprogamable gracias a las nuevas tecnologías ${ }^{4}$.

1 Vázquez Barquero (1998: 98) define el concepto de red como «el sistema de relaciones y/o contactos que vinculan a las empresas, actores entre sí, cuyo contenido puede referirse a bases materiales, información o tecnología».

2 «Los determinantes del potencial de desarrollo regional son recursos que tienen un eminente carácter de "capital” y "público" y que no dependen de la acción de los mercados privados. La cualidad de lo público, no rivalidad y no exclusión, puede subdividirse en cuatro características, a saber: indivisibilidad, insustituibilidad, inmovilidad y polivalencia» (Furió, 1996: 93-94).

3 Al respecto, Valdaliso y López (2000) señalan que los distritos industriales nunca dejaron de estar presentes en un gran número de sectores productivos, ni siquiera durante el apogeo de la gran empresa y la producción en masa.

${ }^{4}$ Castells y Hall (1994) plantean que la flexibilidad es el principal atributo de ciudades y regiones, destacando su capacidad para adaptarse a las condiciones cambiantes de la tecnología, los mercados y la cultura. Su disposición para negociar con las grandes empresas coexiste con los incentivos para que se desarrollen pequeñas y medianas empresas innovadoras. 
Mendras (1999) concluye, una vez efectuada la evaluación de cada modelo nacional de capitalismo, que si el modelo capitalista alemán y el estatista francés son demasiado pesados y rígidos para adaptarse a las nuevas exigencias de la globalización, sólo quedan dos modelos en la competición: el liberalismo inglés y las redes italianas. Para este autor, el modelo liberal servirá de patrón, por la sencilla razón de que basta con no inventar ni hacer nada para que el curso de los acontecimientos conduzca a ello. Por otra parte, este modelo tiene una fuerza ideológica asombrosa. Sin embargo, para este autor, no sería bueno que su sencillez y su espíritu condujeran a imitarlo ya que, por definición, las empresas tienen estrategias pero no moralidad; por tanto, la sociedad debe imponer la suya. Cabe, entonces, preguntarse si las redes italianas pueden ser una alternativa de "capitalismo civilizado". ¿Son los sistemas locales de especialización flexible (los distritos industriales, los entornos innovadores, los sistemas productivos de pequeña empresa... $)^{5}$, sistemas que han sido interpretados como un modelo de industrialización posfordista y cuyo dinamismo ha sido puesto en contraposición con el de la gran empresa, los que humanizan el capitalismo?

En el estudio de las redes se presenta la dimensión territorial como un complejo heterogéneo de empresas mutuamente interdependientes cuya competitividad se deriva de la capacidad del conjunto de minimizar costes y de innovar productos. A esta capacidad se le denomina participación o cooperación económica. Como consecuencia de esta participación en el marco territorial se generan economías externas basadas en el flujo de información y personas y en la existencia de redes de relaciones entre las connotaciones productivas de las empresas y las connotaciones sociales de la población, mediatizados por la cultura social y por las instituciones que prevalecen en el entorno local. De este modo, las empresas externas deben competir no sólo contra una empresa individual, ni siquiera contra un grupo de empresas, sino contra una subcultura entera, esto es, contra una comunidad culturalmente homogénea. Los procesos de desarrollo, desde esta perspectiva, no se producen en el vacío, sino que tienen profundas raíces institucionales y culturales. El desarrollo de una economía «lo promueven, siempre, los actores de una sociedad que tiene una cultura y formas y mecanismos propios de organización. Cada necesidad alienta el desarrollo de formas específicas de organización e instituciones propias que facilitarán o dificultarán la actividad económica, debido a que los agentes económicos toman sus decisiones en ese entorno organizativo e institucional y, por supuesto, no siguen las prescripciones técnicas de los modelos económicos» (Vázquez Barquero, 1999: 242).

La dimensión en red, las economías externas generadas por las interdepen-

5 Véanse Best (1990), Piore y Sabel (1990), Becattini (1979), Brusco (1982; 1986), Bagnasco (1977), Vázquez Barquero (1999). Estos autores analizan las estrategias de las pequeñas empresas locales especializadas en la producción de pequeñas series, ajustadas a la demanda de productos modernos y utilizando la tecnología que les permite competir en los mercados. Estrategias que constituyen una de las formas de organización flexible del modelo de acumulación. 
dencias locales que se crean entre fuerzas sociales y fuerzas económicas (empresas, familias e instituciones) que comparten el mismo territorio local de asentamiento, constituyen una forma de gobernación junto a otras formas como el mercado o la jerarquía. Así, las empresas y los agentes que forman la red (frente al mercado o la jerarquía) se mueven, cada uno de ellos, por intereses concretos como la reciprocidad, la confianza ${ }^{6}$ (frente al precio o la norma). Las fuerzas externas «que empujan a los actores a tomar decisiones son las acciones concretas de las empresas, actores que forman la red y demanda en el mercado o las relaciones jerárquicas en las grandes organizaciones públicas y privadas». Por ello, en contra de la visión neoclásica que se refiere a los empresarios "como competidores que se relacionan a través de las señales del mercado (precio/costes) en su búsqueda de beneficio, el surgimiento y crecimiento de la capacidad empresarial y organizativa en un territorio es el resultado de un proceso conjunto en el que las redes de contactos personales y las acciones estratégicas de los actores permiten a los empresarios realizar sus proyectos de negocio» (Vázquez Barquero, 1999: 103).

La concentración de empresas especializadas en actividades complementarias permite obtener beneficios de las economías externas que surgen en el tejido del distrito industrial, pero hay que subrayar que esta forma de organización industrial es la manifestación de un fenómeno económico mayor: la globalización de la competencia, concretamente la adaptación a los poderes del mercado mundial. En este sentido, Alonso (1999: 127-128) argumenta que con la crisis de los años setenta y la progresiva desregularización y liberalización de todos los mercados durante los años ochenta, la política económica regional ha quedado desestructurada y subsumida en las sucesivas oleadas de reestructuración y flexibilización productiva postfordista. No por casualidad «es en esta época cuando florece el minimalismo de las políticas de desarrollo local empeñadas en neutralizar desde los territorios micro la inocultable agresividad social que estaban tomando los mercados macro. Estos intentos de generar desarrollos concretos y locales "de abajo a arriba" han supuesto, quizás más en su teoría que en su práctica, el intento de aprovechar capital humano y cultural, recursos técnicos materiales y naturales y sobre todo formas de trabajo tradicional de la comunidad para reaccionar contra las negras expectativas que de manera principal sobre el empleo se estaban realizando para las economías que habían entrado en un ciclo de remercantilización total».

En cualquier caso, las políticas de desarrollo local no dejan de ser mitologías de un cierto desarrollo autónomo que, en el fondo, acaban potenciando las

${ }^{6}$ Como señala Vázquez Barquero (1999: 100), «sin confianza no se podría hablar de redes, ni de sistemas productivos locales ni de procesos de desarrollo endógeno (...) Las relaciones de confianza refuerzan los compromisos y la cooperación entre las empresas. Se basan en los contactos personales entre los actores y se fortifican a medida que los lazos entre las empresas perduran en el tiempo y los resultados de la relación fructifican». Véanse, también, Mingione (1994), Piore (1992), Becattini (1992), Pyke y Sengenberger (1992). 
políticas de competencia y rivalidad entre regiones y territorios ${ }^{7}$. En este sentido, estos pretendidos desarrollos autónomos estarían fuertemente condicionados por la evolución de un mercado cada vez más poderoso y una sociedad cada vez más vulnerable frente a los movimientos financieros y las maniobras especulativas de unos capitales internacionales a los que se les han ido abriendo todas las posibilidades de movilidad y de intervención en las políticas macroeconómicas de los Estados ${ }^{8}$. Como sostiene Castells (1997), las empresas medianas y pequeñas continúan bajo el control tecnológico, comercial y financiero de las grandes empresas, que están en el centro de la estructura de poder económico en la nueva economía global. Lo que está en crisis no son las grandes empresas sino, más bien, su modelo de organización tradicional, basado en la integración vertical y la gestión funcional jerárquica ${ }^{9}$. Por tanto, lo que se impone, bajo la cobertura de la globalización competitiva, son redes multinacionales de empresas (grandes, medianas y pequeñas) que colaboran y compiten al mismo tiempo. En la actual economía informacional, concluye Castells, ya no existen empresas completamente independientes y autosuficientes. En este sentido, este autor destaca el modelo de la subcontratación en la que, en la mayoría de casos, el subcontrato industrial tiene el carácter de una "cuasiintegración» que obliga al subcontratista y a sus asalariados a soportar la mayor parte de los riesgos del mercado.

Los distritos permanecen gracias a la fuerte relación que se establece entre empresa, cultura y territorio, pero la pertenencia a un distrito industrial y el disfrute de economías externas de escala no supone una ventaja competitiva permanente, puesto que la globalización del espacio económico aumenta la competencia, reduce las ventajas relativas que proporcionan las economías externas e induce el ajuste de los sistemas productivos locales. Todo ello fuerza a que los distritos industriales se vean impulsados a renovarse y a especializarse continuamente buscando la diversificación y la articulación de las viejas y nuevas actividades ${ }^{10}$. En definitiva, en la economía global, la tendencia es a que los territorios, los entornos locales como las ciudades y las regiones compitan entre sí por mantener las inversiones locales y atraer empresas e inversiones procedentes del exterior.

En esta competencia adquieren especial relevancia factores como la calidad

Como afirma Gorz (1998), pretender resistir nacionalmente, esto es, territorialmente, conduce implacablemente a capitular frente a la globalización. Para este autor, no es contra la globalización qua hay que luchar tratando de sustraerse de ella; hay que luchar dentro de la globalización en curso por una globalización diferente. La resistencia al capital transnacional no suele ser sino ella misma transnacional; la resistencia a los actores de esta globalización exige ante todo agentes de otra globalización, a partir de una visión, una solidaridad, un proyecto de civilización proletaria.

${ }^{8}$ Véase Amin $(1995 ; 1997)$.

9 Para Valdaliso y López (2000), en todo distrito hay una cierta jerarquía y es fácil reconocer un núcleo en la red que puede ser desde una gran empresa que lidera el distrito hasta algún centro de investigación-educación y/o financiero.

${ }^{10}$ Véase Becattini (1987). 
de los recursos e infraestructuras, la capacidad innovadora de las empresas e instituciones, la organización del sistema productivo susceptible de generar economías de escala y bajos costes de transacción, el entorno institucional favorecedor del desarrollo de un clima empresarial y la cooperación y, por último, la existencia de una política de desarrollo local que sea una respuesta estratégica a los desafíos de la globalización. Nos encontramos, pues, frente a un proceso paradójico que Beck (1997) ha denominado como "glocalización», proceso en el que el trasfondo de la economía global está permitiendo acentuar la importancia de lo local. Así, el proceso de globalización ha impulsado también los procesos de desarrollo endógeno. Este desarrollo endógeno se basa en un fortalecimiento de las estrategias relacionales (productivas, tecnológicas y de intercambio) y de sus redes incardinadas en los entornos territoriales locales. De esta manera, la territorialización del impulso de las actividades productivas con un patrón de relaciones basado en la colaboración de los agentes económicos, sociales e institucionales se ha presentado, erróneamente, por algunos autores ${ }^{11}$ como el contrapeso de la pretendida alienación y homogeneización que se derivaría de la globalización.

\section{LA DELIMITACIÓN CONCEPTUAL DE LAS ACTIVIDADES ECONÓMICAS}

En la literatura sobre el tema, se ha considerado que la emergencia de las llamadas regiones o zonas industriales simplifica la toma de decisiones en una situación incierta. Además, se ponen de manifiesto las ventajas que estas regiones o zonas industriales aportan para las empresas ubicadas, y concretamente para los procesos de desarrollo endógeno, al considerar el surgimiento y crecimiento de las empresas, la difusión de las innovaciones y, en definitiva, el propio proceso de cambio estructural.

Ahora bien, el análisis de los distritos industriales ha de comenzar con una descripción de cuáles son sus orígenes en la literatura. Para ello, debemos referirnos a conceptos tales como economías de aglomeración y clusters, entre otros. Existe una larga tradición en economía industrial y regional, que se remonta al siglo XIX, que tiene como objeto explicar la tendencia de la industria a aglomerarse en regiones geográficas particulares ${ }^{12}$.

Con la renovada atención brindada a la dimensión espacial de las actividades económicas, se pueden distinguir dos temas diferentes pero interrelacionados: a) las aproximaciones dirigidas directamente a la identificación de las ventajas provenientes de la aglomeración geográfica, originadas en la pionera definición de Marshall de economías externas ${ }^{13}$; b) el análisis de factores

11 Véase Boisier (1998).

12 Tradición de la que puede formar parte la teoría sobre la desigual distribución regional del capital y el trabajo (Myrdal, 1957).

${ }^{13}$ Los Distritos Industriales marshallianos son los espacios industriales ocupados por indus- 
estructurales y ambientales, los cuales dieron forma a los conceptos de economías locales y actividades de innovación, iniciando la investigación sobre el milieux innovador (Aydalot, 1986), los distritos tecnológicos (Becattini, 1987) y, más recientemente, los sistemas regionales de innovación (Saxenian, 1994) ${ }^{14}$.

Becattini (1994) señala que hay dos resultados de importancia sobre el tema de las pequeñas y medianas empresas que destacan en los últimos años: a) un resultado teórico, desarrollado a partir de ideas de Coase (1991), según el cual en un mundo dominado por la elección entre haber (dentro de la empresa) y comprar (en el mercado), la frontera entre lo «interno» y lo «externo" se modifica de modo tal que el concepto mismo de dimensión de la empresa debe ser replanteado; b) un resultado empírico, según el cual la eficiencia de la empresa no depende de su dimensión como tal, sino del bien que trata de producir y de la interacción entre condiciones socioculturales y técnicas en las cuales se realiza el proceso productivo ${ }^{15}$.

Algunas de las contribuciones de la economía neoclásica son fundamentales para explicar la existencia de los distritos industriales. Entre ellas destacamos el concepto de economías de aglomeración, que marca las ventajas existentes entre la concentración territorial de las actividades económicas respecto a la dispersión de las mismas. Las economías de aglomeración fueron clasificadas por Richardson (1969) en las siguientes tres categorías: 1) economías de escala o internas a la empresa; 2) economías de urbanización, externas a la empresa y al sector productivo, y 3) economías de localización, externas a la empresa pero internas al sector productivo del que participa la empresa.

1) Economías de escala: surgen de la posibilidad de repartir los costes fijos entre un número mayor de productos, reduciendo así los costes medios.

2) Economías de urbanización: se refieren a las relaciones que pueden existir entre actividades económicas de sectores diversos localizados en el mismo lugar (generalmente una ciudad).

trias especializadas en un mismo sector, cuya dinámica productiva se caracteriza por la generación de externalidades que actúan reduciendo los costes de producción. Véase Becattini (1979).

14 Vázquez Barquero (1999: 110) argumenta que la noción de distrito es un concepto «un tanto limitante a la hora de considerar qué actividades productivas son el motor del crecimiento ya que desconoce el papel de los servicios en los procesos actuales de cambio. La noción de distrito industrial (...) no confiere a la innovación el papel estratégico que tiene en la dinámica industrial. Y por último, considera al territorio como un espacio con fronteras demasiado rígidas. Por ello la noción entorno local ("milieu"), tal como lo han conceptualizado los grupos de investigación que forman la asociación GREMI (Group de Recherche Européen sur les Milieux Innovateurs) (...), amplía y complementa el concepto de distrito industrial, lo que permite considerar algunos de los factores que condicionan la respuesta de las empresas y territorios a los desafíos de la globalización, y, por tanto, interpretar la dinámica económica actual». El concepto de entorno local incorpora la red de relaciones entre los actores del territorio, ampliando así la noción de distrito industrial. Además, incorpora la dimensión de las estrategias que los actores ponen en marcha para el sistema productivo en su conjunto, entre las que destaca la capacidad de aprendizaje y la intervención en los procesos de cambio de las economías locales.

${ }_{15}$ Véase Furió (1996). 
3) Economías de localización: comprenden las ventajas del establecimiento de relaciones entre actividades económicas correlacionadas sectorialmente. Se destacan tres tipos de relaciones o conexiones ${ }^{16}$ :

a) Conexiones de producción: la presencia de diversas empresas del mismo sector permite una mayor disponibilidad de materias primas, semielaboradas, mano de obra especializada y maquinaria.

b) Conexiones de servicio: la presencia de un número importante de empresas del mismo sector hace que estén presentes también firmas especializadas en las actividades relativas al mantenimiento de las instalaciones de las mismas.

c) Conexiones de mercado: la presencia de los compradores de los productos intermedios, entre ellos las grandes empresas, es una ventaja para la instalación de los proveedores de estos bienes.

Además de estas conexiones directas entre las empresas, existen ventajas indirectas que surgen del nivel de información técnica y de mercado presente en el área, fenómeno que Marshall denomina «atmósfera industrial» ${ }^{17}$. Esta cultura industrial permite una rápida difusión de los procesos tecnológicos e innovadores, proporcionando una mayor competitividad. En términos más generales, las economías de localización reducen los costes de transacción ${ }^{18}$. La calidad de las relaciones entre los operadores, gracias a la cercanía geográfica y los contactos cara a cara, puede facilitar la elección de la empresa entre jerarquía y mercado.

El fenómeno de la concentración espacial de la producción, y su persistencia a través del tiempo, fue primeramente observado por Marshall, quien enumeró tres ventajas fundamentales (o externalidades) para firmas localizadas en un área determinada:

a) Un mercado de trabajo cualificado, con competencias industriales específicas, el cual, desde el punto de vista de las empresas, las provee de oferta laboral.

b) La disponibilidad de inputs no comercializables e intermedios, ofertados por proveedores locales.

c) La mayor facilidad para la transmisión de nuevas ideas (efecto derrame o spillovers de transmisión de información), lo cual permite un incremento de

16 Véase Ciciotti (1993).

17 Vázquez Barquero (1999) señala la relevancia del papel que juegan las atmósferas industriales específicas en la red de relaciones establecidas en el territorio. Esta atmósfera se concreta en el intercambio de ideas y conocimiento en la interacción entre la mano de obra cualificada. Asimismo, puede haber intercambio de recursos y productos. Según este autor, la acumulación de conocimiento tiene un efecto multiplicador sobre el requerimiento de fuerza de trabajo más cualificada, lo que constituye uno de los recursos endógenos y, al mismo tiempo, una fuente de atracción para inversiones externas.

18 Véanse Ciciotti (1993), Vázquez Barquero (1999). 
la eficiencia en la función de producción, debido a mejoras técnicas, organizacionales y de producto.

Las economías estáticas y dinámicas fueron identificadas por Marshall como una categoría de posibles efectos de la aglomeración espacial de las actividades económicas, remarcando la eficiencia y el crecimiento de las firmas localizadas en el cluster $^{19}$. Harrison et. al. (1996) realizan una distinción entre economías de aglomeración estáticas y dinámicas. Las primeras ocurren cuando los costes de producción unitarios de una firma son menores (en el contexto de una aglomeración relativamente densa de empresas o de recursos especializados) que los resultantes de localizarse en forma dispersa. Las economías de aglomeración dinámica se refieren a la mayor propensión a que exista un aprendizaje tecnológico (no sólo simples reducciones de costes de producción con una tecnología dada) en lugares de densa urbanización, distritos o aglomerados, respecto a sitios con menor densidad.

Un hecho importante de las economías de localización, que las diferencia de otras economías generadas por materiales o trabajo más barato, es que dependen de la coincidencia de decisión de un número de firmas. Este hecho da lugar a razonar en términos de una realidad no visible, más potente que un simple hecho de mercado. Hay lugar para pensar en una razón más poderosa, basada en distintos hechos, no sólo económicos, y no exclusivamente en un simple mecanismo de localización industrial.

Usualmente existe una distinción entre los diferentes tipos de fuerzas de aglomeración que modelan la organización espacial. Por un lado, tenemos las economías de urbanización (entre ellas, los efectos «derrame» o spillovers), las cuales atraen toda clase de actividades económicas a ciertas áreas. Esto provoca que surjan ciertas especializaciones regionales que varían a través de las localizaciones. Por otro lado, existen economías de aglomeración que se producen en agrupaciones espaciales, por firmas que toman actividades relacionadas o similares. Esta clase de fuerzas suelen ser industrias específicas y producir mecanismos acumulativos, los cuales permiten a las localidades huéspedes incrementar sus competencias productivas, tecnológicas y organizativas. Más generalmente, las externalidades de la urbanización existentes entre diferentes industrias pueden ser esencialmente descritas como economías externas resultantes del crecimiento de toda la actividad económica en un área particular, mientras que las externalidades localizadas son economías externas a las firmas pero generadas entre las firmas de la industria (o el sector). Sin embargo, es difícil establecer una real distinción en ambos casos de economías, originadas por la eficiencia y la intensidad de los vínculos establecidos entre los actores

19 Porter (1990) identifica los casos concretos de distrito industrial como agrupamiento (cluster) entendido como conjunto de sectores productivos competitivos interrelacionados, destacando el entorno local y la rivalidad entre competidores como fuentes de ventaja competitiva a partir de la aplicación del modelo de diamante. 
locales, actuando como barreras a la entrada para las nuevas firmas y creando un bucle con una ventaja inicial en las áreas donde existen.

Uno de los aspectos a destacar de la localización de la producción en el espacio, que hace de su estudio un problema que debe abarcar más que los hechos de economía pura, es su carácter path-dependence (que siguen un itinerario marcado), es decir, su determinación por aspectos históricos y culturales que van más allá de los conceptos utilizados por la teoría económica para explicar sus características. En palabras de Krugman (1991: 80), «si existe una sola área de la economía en la cual la path-dependence es acertada, esta área es la geografía económica — la localización espacial de la producción». Las fuerzas aglomerativas provienen también del lado de la demanda, particularmente en relación con la estructura input-output de las actividades industriales, las cuales crean vínculos hacia delante y hacia atrás, imprimiendo cierta dinámica al sistema. La concentración de la producción es promovida por la proximidad a los proveedores, lo cual reduce los costes de la firma, o por la proximidad a los compradores de bienes intermedios, lo cual incrementa los beneficios de las firmas proveedoras. Se debe aclarar que, como todo sistema de relaciones, la importancia de los vínculos interfirma cambiará dramáticamente de acuerdo a la firma o al ambiente industrial, dependiendo de la escala y tecnología.

En resumen, los efectos de la aglomeración han sido tradicionalmente analizados en términos estáticos, considerando principalmente cuestiones de eficiencia (economías de escala, costes de transporte y transacción, vínculos de input-output). Las aglomeraciones dinámicas hacen hincapié más sobre los procesos de aprendizaje tecnológico y acumulación de conocimiento que afectan las trayectorias de crecimiento, no sólo una cuestión de costes de producción. Por otra parte, las externalidades que arrancan de Marshall son muy diversas. En este sentido, se han hecho intentos de sistematización y de categorización de estas externalidades. Glaeser et al. (1992) estudian el papel caudal que tienen las ciudades en los procesos de surgimiento de información (knowledge spillovers), los procesos mediante los cuales los conocimientos técnicos existentes en el interior de las unidades productivas se reparten por un determinado territorio. Estas externalidades son el eje fundamental del crecimiento ${ }^{20}$. Si consideramos que la proximidad geográfica facilita este intercambio de ideas, el knowledge spillovers tendría que ser especialmente importante en las ciudades, ya que son unos ámbitos donde se dan las condiciones ideales para este intercambio. Glaeser et al. centran su estudio en tres teorías relativas a la aproximación que

${ }^{20}$ Las economías externas aparecen principalmente, en opinión de Krugman (1997), de dos formas: por un lado, las que tienen que ver con la difusión del conocimiento entre las empresas, que dan como resultado las economías externas tecnológicas. El resultado del intercambio es un proceso de crecimiento acumulatico de la base del conocimiento en la economía nacional. Por otro lado, las economías externas pecuniarias dependen directamente del tamaño del mercado, en el sentido en que una industria nacional fuerte crea potencialidades de mercado importantes para el trabajo especializado y los proveedores. 
dan lugar al fenómeno de las externalidades. De esta manera tenemos las externalidades del tipo Marshall-Arrow-Romer (MAR), las definidas por Porter y, finalmente, las nombradas por Jacobs.

Las externalidades del tipo Marshall-Arrow-Romer (MAR) son aquellas de carácter intraindustrial en un contexto de monopolio local. Es decir, que hablan de los efectos que se generan entre empresas de un mismo sector en unas condiciones que un número reducido de empresas están instaladas en una localidad. En un caso de este tipo, pues, tanto la información que circula como las necesidades en materia tecnológica, de servicios, o de materias primas, estarán muy relacionadas al tratarse de empresas dedicadas al mismo sector de actividad. El modelo de competencia al que nos lleva este planteamiento es el de monopolio local. En este sentido, Callejón y Costa (1995) hablan de dos pautas de localización de gran significación: la concentración de las actividades industriales y la especialización local en unas cuantas, pocas, de estas actividades. Porter, en cambio, considera que la concentración geográfica de las industrias estimula el crecimiento, pero cree que un modelo de competencia local es mejor que no el monopolio; se trata, pues, de un modelo de competencia intraindustrial en un mercado competitivo ${ }^{21}$. Jacobs, finalmente, afirma que lo que estimula el crecimiento es la diversidad y no tanto la especialización geográfica. Jacobs es, pues, favorable a un modelo con fuerte competencia interindustrial a nivel local ${ }^{22}$. Posteriormente ha habido algunas sistematizaciones de las externalidades, como la de Henderson et al. (1995), basada en parte en el trabajo antes citado de Glaeser et al., en dos tipos, las estáticas y las dinámicas.

\section{Externalidades}

\section{Localización}

\begin{tabular}{lll}
\hline Estáticas & $\begin{array}{l}\text { Las empresas se benefician de la presencia } \\
\text { de otras empresas del mismo sector }\end{array}$ & $\begin{array}{l}\text { Las empresas se benefician de la presencia } \\
\text { de empresas de diversos sectores }\end{array}$ \\
\hline Dinámicas & $\begin{array}{l}\text { (MAR) La difusión de los conocimientos se } \\
\text { hace entre empresas del mismo sector }\end{array}$ & $\begin{array}{l}\text { (Jacobs) La difusión de los conocimientos } \\
\text { va ligada a la existencia de una diversidad } \\
\text { sectorial }\end{array}$
\end{tabular}

FUENTE: Henderson et al. (1995).

Véase Porter (1991).

22 Véase Jacobs (1984). 


\section{LA DINÁMICA DE LOS CLUSTERS}

Los clusters pueden ser identificados en términos amplios como aglomeraciones geográficas de firmas, dotadas de una «coherencia» económica y social. Así como la producción, las actividades de innovación tienden a ser espacialmente concentradas, y esto puede ser atribuido nuevamente a los casos específicos de economías de aglomeración (externalidades de conocimiento y spillovers). Es decir, la existencia de una "atmósfera industrial», en términos de Marshall, producida por la acumulación de habilidades, know-how, en un espacio físico determinado, otorga importantes ventajas para la localización de las firmas. Es evidente la existencia de determinantes históricos, geográficos y culturales.

Una localización común ofrece similares condiciones culturales, las cuales mejoran u optimizan la velocidad y la facilidad de transmisión del conocimiento. El cluster local, como ente, ofrece el ambiente correcto para el desarrollo de un lenguaje común, códigos de comunicación compartidos, valores colectivos e instituciones localmente aceptadas. Es necesario, por lo tanto, superar el análisis puramente tradicional de los factores económicos, para profundizar el estudio sobre las características de los sistemas sociales y las instituciones que amparan este tipo de localizaciones.

La explicación más plausible de la tendencia inercial de la actividad económica para aglomerarse es que las decisiones locales de las firmas están basadas en factores que no sólo incluyen la pura maximización de beneficios. El proceso de decisión de la localización incluye factores no cuantitativos, como la relación local entre firmas y trabajadores, la actitud ante la innovación tecnológica y la disponibilidad de infraestructuras intangibles, entre otros.

La interacción entre actores económicos, socioculturales e institucionales sigue patrones de cooperación y competencia, los cuales crean un mecanismo estable de acumulación y difusión del conocimiento. Por un lado, la presión de la competencia y el empuje asociado a innovar proveen la dinámica guiada por la ventaja, que crea un círculo virtuoso. Por otro lado, la concentración espacial incrementa la intensidad de interacción entre los actores del sistema, aumentando las posibilidades de colaboración, para lo cual se precisa una mediación de las instituciones locales. Por lo tanto, la llave de la ventaja competitiva de los clusters descansa en la relación entre competición y cooperación de las firmas que operan en el mismo sector o similar.

Tratando de sistematizar lo desarrollado en el párrafo anterior, podemos afirmar que las firmas en un cluster se relacionan entre ellas en tres diferentes niveles: 1) verticalmente: vínculos, transacciones, cooperación; 2) horizontalmente: competición, y 3) espacialmente: proximidad, compartir ambientes culturales e institucionales. Los tres tipos de relaciones implican no sólo flujos físicos de inputs u outputs, sino también intercambio de información, conocimiento y experiencia, los cuales tienden a replicar a través del tiempo, causando una inercia en una localidad económica. Para sintetizar, las relaciones más 
importantes de los sistemas son: a) las relaciones con las fuentes de información de la firma, las cuales están fuertemente influenciadas por la proximidad espacial; b) el uso de canales informales para la difusión de conocimiento (conocimiento tácito), y $c$ ) la naturaleza de las capacidades innovativas, las cuales son altamente path-dependence y geográficamente específicas.

\section{PUNTUALIZACIONES SOBRE LOS DISTRITOS INDUSTRIALES}

El término Distrito Industrial fue introducido por primera vez por Alfred Marshall. Posteriormente, el concepto fue reintroducido en la literatura económica por Becattini (1978), cuya definición de distrito industrial es la de ser una entidad socioterritorial caracterizada por la presencia activa, en un área territorial circunscrita, naturalmente e históricamente determinada, de una comunidad de personas y de una acoplación de empresas industriales. Para Becattini (1990), las ventajas de la localización en un distrito industrial se derivan de un amplio conjunto de externalidades que se asocian a: a) la especialización de las empresas en una fase de producción, posibilitando que se consiga un equilibrio en condiciones de competencia y rendimientos crecientes; b) la atmósfera industrial, local, y c) la existencia de externalidades vinculadas a la formación y a la existencia de un mercado de trabajo especializado.

Es útil destacar los aspectos distintivos con respecto a los clusters genéricos, que determinan los elementos caracterizantes de los distritos industriales: 1) concentración de producción y actividades innovadoras, ambas a nivel geográfico y sectorial; 2) un entorno (background) social y cultural común, y 3) organización de vínculos entre actores pertenecientes al negocio o no, en redes (networks) formales e informales ${ }^{23}$.

Sin embargo, la definición de Becattini ${ }^{24}$ y la literatura escrita en los últimos veinte años permiten hablar de los distritos industriales como un ente con una «identidad y autoconciencia» específica ${ }^{25}$ :

1) La concentración geográfica de actividades económicas ocurre en pequeñas áreas, las cuales a menudo pertenecen a la periferia. Más generalmen-

${ }^{23}$ Estos factores se corresponden largamente con los tres niveles de relación (vertical, horizontal, territorial) existentes entre firmas localizadas en un cluster.

${ }^{24}$ Por otra parte, Becattini (1979) se aleja de posiciones simplistas que asocian las externalidades y las economías de aglomeración con el tamaño urbano y se centra en los aspectos relacionados con la organización industrial, el progreso técnico, la historia económica y los mecanismos sociales e institucionales que cohesionan los intereses de los sujetos que interactúan en el territorio.

${ }^{25}$ «El lugar es geografía, una localización de la política; la comunidad evoca las dimensiones sociales y personales del lugar. Un lugar se vuelve comunidad cuando la gente utiliza el pronombre "nosotros". Hablar así requiere un apego personal, no geográfico; una nación puede constituir una comunidad cuando la gente traduce las creencias compartidas y los valores en prácticas concretas y cotidianas» (Sennet, 2000: 144-145). 
te, la proximidad geográfica está siempre asociada con sectores minúsculos y especializados.

2) El background social y cultural presenta una homogeneidad fuerte, característica que se ve debilitada en clusters limitados en áreas urbanas y centrales. Los orígenes históricos, los valores sociales y los hábitos culturales son profundamente compartidos por los miembros de la comunidad y son funcionales al tipo de actividad económica desarrollada en el distrito industrial. Esta homogeneidad de valores y reglas sociales previene conflictos y refuerza la confianza, liderando patrones de complementariedad y cooperación entre actividades y actores. La noción de competencia está implícita en la definición del ambiente de las firmas que producen bienes y servicios similares, pero, a su vez, la colaboración tiende a ser la dimensión prevaleciente en los distritos industriales. Por lo tanto, los vínculos "horizontales» entre firmas tienen una naturaleza cooperativa que es complementaria a su naturaleza competitiva intrínseca.

3) Los networks económicos e institucionales son centrales en los distritos industriales, y están modelados por el conjunto de valores comunes que distinguen el ambiente local. Dichos networks acompañan los vínculos estáticos y dinámicos entre firmas, ya que modelan la organización de la división del trabajo, las relaciones input-output con proveedores y clientes, los intercambios de información, así como también las conexiones entre agentes económicos e instituciones locales. En un distrito industrial, la naturaleza informal y el «cara a cara» de los networks a menudo es más poderoso que las relaciones formales. Los distritos industriales aparecen entonces como clusters donde se desarrollan relaciones peculiares entre las firmas y la comunidad local.

La división del trabajo es una característica distintiva de los distritos industriales. Las empresas se dedican a trabajar en una fase o algunas fases de los procesos de producción. La fragmentación de la actividad industrial en diferentes tareas de trabajo y producción tomadas por las empresas provee una variedad aún mayor que incrementa las economías de diversificación (repartición de los costes fijos entre productos diferenciados), esta vez interna a las firmas subcontratistas, que llevan a cabo trabajos similares para diferentes clientes.

Los distritos industriales son habitualmente identificados con respecto a otros tipos de aglomeración industrial por el ambiente social y cultural en que se desarrollan, que permite vínculos o relaciones que van más allá de aspectos económicos. La confianza es el resultado de este tipo de vínculos que, aun no siendo fácilmente mensurable, representa la base para la interacción social, permitiendo que valores, reglas y conductas puedan ser compartidos y disfrutados por generaciones de individuos. La influencia de la confianza y la colaboración hacen prominente el rol de los individuos en las actividades económicas: uno de los temas centrales de los distritos industriales es entonces la maximización de la frecuencia y la intensidad de las comunicaciones interpersonales. Este factor es crítico para la innovación, descontando que la confianza 
y la colaboración reducen la incertidumbre, riesgos y costes de las actividades innovadoras del distrito industrial. Sin embargo, el distrito industrial es más que la suma de los individuos que interactúan unos con otros en un ambiente local, así como también que la población de las firmas es más que el agregado de unidades de producción. Los networks son esenciales para el desarrollo del distrito industrial y se componen de instituciones económicas y no económicas. El hecho particular de la existencia de un balance entre competición y colaboración en un distrito industrial debería ser otra fuente de discusión metodológica. Por un lado, la estructura competitiva siempre ha sido prevalente en los ámbitos locales; por otro, se conjuga con la atmósfera de colaboración del distrito industrial. El rol prominente de los individuos y las relaciones informales, la estabilidad del ambiente y la homogeneidad de valores brindan el apoyo a una sociedad con un interés general en la colaboración. Esta propensión a la cooperación voluntaria es un hecho con un impacto enorme en la performance de los distritos industriales. Estos aspectos tienen también un lado negativo, ampliamente discutido en la epistemología tradicional, y es el hecho que la combinación de los elementos económicos y socioculturales tiene una distribución heterogénea a lo largo de las localizaciones, lo cual implica problemas de replicabilidad de los distritos industriales. ¿Es posible replicar un distrito industrial como elemento de política industrial? Dado que son básicamente path-dependence (su desarrollo depende fuertemente de factores históricos y socioculturales), es cuestionable suponer que los mecanismos de acumulación, y por ende de aglomeración, puedan ser replicados. Sin embargo, la presencia de distrito industrial en diferentes partes del mundo indica que existe un amplio rango de entes asimilables al concepto de distrito industrial. Esto lleva a la idea de infinitos modelos potenciales de distrito industrial; en principio, nada parece refutar el hecho que lecciones valiosas sean aplicadas con suceso en diferentes contextos. Según sean más o menos favorables las condiciones de mercado, tecnológicas y dependiendo de la rama de actividad, será uno u otro grado de integración de la coordinación en el distrito industrial. A partir del grado de integración de la coordinación, Valdaliso y López (2000) distinguen entre distritos nucleados y jerárquicos y distritos más cooperativos. En estos últimos se observa una gran autonomía de las firmas en el diseño, fabricación y distribución, pero al mismo tiempo cooperan con otras empresas para mantener la compatibilidad entre sus productos y sacar mayor rendimiento a los conocimientos acumulados en la utilización de nuevas tecnologías. En los distritos jerárquicos hay una predominancia de la empresa que concentra el montaje final, o bien se establecen redes nucleares si los conocimientos tecnológicos implicados son muy altos, cuando existen elevadas economías de escala y altos costes de transacción. 


\section{PARA UNA EPISTEMOLOGÍA DE LOS DISTRITOS INDUSTRIALES}

En el punto anterior se efectuó un recorrido por los aspectos teóricos de la rama industrial que estudia las economías de aglomeración y, especialmente, los distritos industriales. Ahora pretendemos analizar los elementos que juegan un papel preponderante en la construcción de esta "teoría», donde los distritos industriales son la unidad de análisis. Este estudio no agota, ni pretende agotar, todas las posibles formas de enfrentar la epistemología de los distritos industriales, sino que procederemos a analizar algunos aspectos puntuales, escogidos por la relevancia que poseen, para encarar su estudio.

\section{La unidad de análisis}

El tratamiento de los distritos industriales como unidad de análisis requiere añadir algunos elementos que son ignorados por la teoría económica tradicional. En ella, los niveles de análisis van desde la empresa individual, pasando por el estudio de sectores industriales y llegando al nivel agregado de la macroeconomía nacional. No existe un ente intermedio con las características del distrito industrial, que comprenda en sí aspectos territoriales y socioculturales. Para remediar estas carencias es necesario entender la producción como un proceso intrínsecamente situado, considerando la variable espacio como determinante de los procesos de desarrollo locales ${ }^{26}$. La variedad de los fenómenos productivos presenta dimensiones diversas: nacional, sectorial, empresarial y local. Los sistemas locales, en esta matriz de la complejidad industrial, tienen un rol específico, esencial y no sustituible ${ }^{27}$.

Lo específico de los sistemas productivos locales tiene que ver con el modo en que la economía del sistema de empresas se integra con el ambiente que lo circunda. En el sistema local se encuentra una historia natural y humana, que provee a las organizaciones productivas algunos inputs esenciales, como el trabajo, la capacidad empresarial, la infraestructura material e inmaterial, la cultura social y la organización institucional. La llave de lectura territorial hace visible de este modo la naturaleza circular del proceso de producción: producir no significa sólo transformar un conjunto de inputs en un output según ciertos procedimientos técnicos, sino también reproducir los factores materiales y humanos de los cuales se alimenta el mismo proceso productivo. En otros términos, la producción de las mercancías incluye la reproducción social del organismo productivo: un proceso productivo verdaderamente completo debería coproducir, junto a las mercancías, los

26 Véase Vázquez Barquero (1999).

${ }^{27}$ Véase Becattini y Rullani (1994). Por otra parte, en el momento actual las condiciones competitivas de los mercados exigen de los territorios recursos y activos no sólo genéricos, sino también específicos. Por ejemplo, las infraestructuras con valor estratégico, la cualificación de la fuerza de trabajo, la cultura empresarial y tecnológica, entre otros. 
valores, conocimientos, instituciones y el ambiente natural que sirven a perpetuarlo ${ }^{28}$.

La especificidad y relevancia teórica del contexto local respecto a otro tipo de contexto está en la oportunidad que éste ofrece de examinar en vivo la producción como fenómeno circular, que pone en relación los aspectos técnicos y económicos con los sociales, culturales e institucionales. El sistema local es un lugar de acumulación de experiencias productivas y de vida, y de producción de nuevo conocimiento; éstos son los recursos críticos del desarrollo del capitalismo industrial contemporáneo. Por tanto, para releer la economía desde la óptica de los sistemas locales, el punto de partida más inmediato debe ser el concepto de proceso productivo completo, en el cual la actividad de producción de mercancías se realiza junto con la actividad de reproducción de los factores humanos y materiales de la producción misma ${ }^{29}$.

Con estricto rigor, el único ejemplo de un proceso productivo completo podría estar representado por el sistema-mundo. Si del sistema-mundo se pasa a examinar un subsistema social territorialmente definido tenemos, entonces, unidades de análisis de procesos productivos cuasi-completos, en los que se trata básicamente de identificar el núcleo esencial de las condiciones económicas y socioculturales para la propia reproducción y desarrollo. Desde el punto de vista económico, cada sistema local identifica un segmento del proceso productivo local, el cual tiene una propia autonomía parcial y una propia reconocibilidad, porque posee una identidad que, en cierto modo, regula, dirige y finaliza los procesos de evolución generados por la dinámica competitiva de la economía global. Son estas propiedades que hacen al sistema global una unidad de investigación conveniente.

Se trata de: 1) aislar un "pedazo de realidad social» que responda de un modo aceptable a las exigencias de la unicidad y complejidad mencionadas, y 2) colocar esta unidad en un nivel de agregación accesible a la investigación de campo $^{30}$. Una unidad de nivel intermedio con estas características puede ser el sistema productivo local. El distrito industrial no es más que un tipo de sistema productivo local. Los Sistemas Productivos Locales se caracterizan por su especialización en torno a un sector industrial verticalmente integrado; lo que

28 Véase Becattini y Rullani (1994). Aydalot (1985) enfatiza la necesidad de desarrollar la idea de «modo de producción regional». Éste estaría caracterizado por las formas organizativas, técnicas y sociales propias de un territorio en cuestión.

29 Bianchi (1990) también acentúa la dimensión social de los distritos industriales, lejos de poder ser concebidos como formaciones económicas abstractas. De ahí que proponga, como marco interpretativo para su análisis, hacer referencia al modelo de producción, al modelo espacial y al modelo social. De la integración de la sociedad y las instituciones en los procesos productivos dependerá, en buena medida, la capacidad de respuesta del territorio y los actores económicos. Los procesos industriales endógenos son resultado de la integración del sistema productivo en la comunidad local. En esta integración juega un papel relevante no sólo la cooperación empresarial, sino también las estructuras familiares, las tradiciones locales, el sistema de valores, el modelo de institucionalización de los comportamientos sociales y la difusión de la información y el conocimiento.

30 Véase Becattini y Rullani (1994). 
significa que las empresas realizan sólo las funciones complementarias de su actividad de especialización. Esta organización del proceso productivo da lugar a que, dentro de un ámbito local, se realicen gran parte de las actividades industriales necesarias para la obtención del producto final, que define el tipo de actividad que se realiza en la zona. Por otra parte, la ventaja competitiva de este modelo industrial depende de la capacidad de las empresas para aprovechar las economías externas y establecer relaciones de cooperación. De este modo, la red de acuerdos - formales e informales - que se configura en el marco del sistema productivo permite que los recursos utilizados individualmente eleven los rendimientos de los recursos de otras empresas. En otros términos, significa que en el territorio se concentran economías externas a las empresas que son utilizadas de forma decisiva por éstas para alcanzar el nivel de eficacia y eficiencia que les permite ser competitivas. Cooperación, flexibilidad y cohesión socioindustrial son factores decisivos ${ }^{31}$.

\section{La Economía Regional y la variable espacio}

Históricamente, la Economía Regional propiamente dicha nace como disciplina autónoma bajo la presión de una exigencia de política económica: hacer frente a los problemas derivados de los diferenciales regionales en el ingreso y en la ocupación que las fuerzas de mercado no estaban en grado de eliminar. Anteriormente, varios autores habían intentado abordar separadamente algunos problemas derivados de la introducción de la variable espacio en el análisis económico. Implícito en este enfoque estaba la existencia de un único modelo de desarrollo económico y territorial y, por tanto, el problema consistía en individualizar las causas del retardo, para después eventualmente actuar con los instrumentos oportunos, siempre que el mercado no estuviera en grado de garantizar en un tiempo razonable la superación en las diferencias de crecimiento.

Diversas causas, tales como los escasos resultados obtenidos por las políticas regionales, los cambios ocurridos en la tecnología, en los modelos organizativos de la empresa, en la división internacional del trabajo y, más generalmente, en el paradigma técnico-económico dominante, han llevado a repensar el rol del espacio en la economía. La lógica resulta en cierto sentido invertida: no se trata de entender por qué el desarrollo económico, abstractamente concebido para prescindir de cualquier consideración espacial, sea más o menos intenso en determinadas áreas, sino, al contrario, comprender en qué medida el espacio puede determinar el desarrollo económico de un área específica. En este sentido, el concepto de espacio toma otro significado: no es sólo un elemento de fricción para la empresa en el acceso a los inputs producidos o a los mercados, sino que se convierte en un factor fundamental en los procesos de desarrollo local. El espacio influenciará los procesos empresariales, los modelos

31 Véase Vázquez Barquero (1993; 1999). 
organizativos de las empresas, su capacidad innovadora, y la entera capacidad de desarrollo y competencia de los sistemas económico-sociales-territoriales.

Para realizar un mejor análisis económico se deben reforzar los aspectos regionales respecto a aquellos espaciales, dado que no se trata de integrar la variable espacio en el modelo económico general neoclásico, sino de identificar las características propias del desarrollo de los sistemas económico-sociales-territoriales.

Dentro de la teoría tradicional del crecimiento tampoco se da al factor territorio la relevancia que debe tener. Si bien es cierto que la dimensión espacial en los problemas de elección está incorporada en los modelos en su forma de "distancia» (costes de transporte, falta de información, inmovilidad parcial de los factores productivos, etc.), no existe todavía un reconocimiento de los efectos sobre la dinámica de la diversidad física, geográfica y sociocultural ${ }^{32}$.

Es de nuestro interés razonar sobre el problema del crecimiento de los sistemas económicos territoriales, para los cuales el contexto socioeconómico "espacializado" resulta una componente propia del proceso productivo y, por lo tanto, está sujeta a graduales transformaciones. El ambiente es una variable que puede ser afectada por los agentes más dinámicos, mientras que puede ser una restricción para aquellos más conservadores. Es por esto que el espacio no puede expresarse sólo en términos físicos o de dotaciones de infraestructura o factores, sino que debe incorporar la naturaleza de los sujetos económicos que operan en él, así como las relaciones existentes entre ellos. En definitiva, el espacio no es sólo un mero contenedor de la actividad económica ni un factor más de producción, sino que tiene un poco de ambas cosas a la vez. En esta línea de análisis, la inclusión de los distritos industriales como unidad de estudio de los procesos de crecimiento regional aporta un tratamiento del factor espacio que comprende las particularidades mencionadas.

Un elemento importante del concepto de industria acuñado por Becattini (1979) es la familia de definiciones denominadas sociológicas, en las cuales el elemento caracterizante está constituido por la consciencia del sujeto de pertenecer a una determinada industria. Mientras que desde el punto de vista de la epistemología tradicional de la economía estas definiciones, dados sus problemas de mensurabilidad, se descartan o se mencionan pero no pueden ser utilizadas, consideramos que, aun pagando un precio muy alto en términos de metodología, vale la pena detenerse a analizarlas. El «sentido de pertenencia» es difícil de medir, pero no por eso menos real, y creemos que hay un consenso sobre el hecho de que, cuando existe, es una fuerza social de primer orden. Basta pensar el rol que éste juega en el movimiento social y político de los trabajadores, para concluir que una situación no es la misma después de que aquel sentido de pertenencia haya intervenido.

Por tanto, las definiciones sociológicas, en cuanto incorporan los patrones socioculturales de un específico itinerario histórico, son la unidad mejor adap-

32 Véase Bramanti y Miglierina (1995). 
tada al estudio de un cierto proceso de desarrollo. El sentido de pertenencia, las relaciones de rivalidad, los procesos imitativos, son factores de unificación y de separación entre grupos humanos, capaces de influir notablemente en los procesos sociales y, por ende, en los procesos económicos. Un estudio de los procesos productivos que no tenga en cuenta estos factores, y trate de "encajar» el complejo de las relaciones sociales en una estructura clasificatoria construida en base a modelos "geometrizantes» de individuo, familia o empresa, perderá en el análisis toda la complejidad y la riqueza de los comportamientos específicos. La incorporación de los factores socioculturales e históricos al análisis se puede realizar mediante una mayor consideración de los efectos del «ambiente» del territorio en los procesos económicos. Tomando como unidad de análisis el distrito industrial se pueden incorporar estos factores y enriquecer así el estudio de los procesos productivos; concretamente, el concepto desarrollo económico local se apoya en la idea de la posibilidad de desarrollar economías de escala aprovechando recursos potenciales todavía sin explorar. El concepto de desarrollo económico local está estrechamente ligado al mantenimiento de rendimientos crecientes de las economías locales, rendimientos que aseguran mayores estándares de nivel de vida para la población.

Vázquez Barquero (1999) señala tres rasgos característicos del concepto de desarrollo local: en primer lugar, hace referencia a procesos de acumulación de capital en ciudades, comarcas y regiones concretas; en segundo lugar, requiere la organización sistemática de las unidades de producción, organización que tiene mucho que ver con las formas socioinstitucionales presentes en el territorio (familia, instituciones, etc.); en tercer y último lugar, el propio territorio es sujeto de transformaciones y cambios originados tanto por factores de carácter exógeno como de carácter endógeno. Especialmente, adquieren relevancia los factores próximos a la propia dinámica de funcionamiento del sistema socioeconómico local en el desarrollo de cambios estructurales que hagan al territorio más competitivo.

El Distrito Industrial constituye una «identidad localizada» (en esta determinación están su fuerza y debilidad) de las relaciones interindustriales, que presenta un carácter razonable de estabilidad en el tiempo. En efecto, su naturaleza compuesta, tendencialmente plurisectorial, le da una estabilidad que una unidad como la industria en sentido estricto no posee, aun en medio de procesos de cambio muy intensos. Esto hace posible un estudio intenso para revelar sus características permanentes, las leyes de su formación, de su mantenimiento y decadencia. Paradójicamente, cuanto mayor es la capacidad del distrito de renovarse, de desplegar nuevos sectores, de articular fases de la producción más especializadas, más aún mantiene su identidad como distrito industrial.

Siguiendo el objetivo de vivificar la investigación empírica, de darle una dimensión social y cultural, en la delimitación y en el examen profundo de esta realidad socioterritorial se realiza la confluencia de las competencias del historiador, del geógrafo, del economista, del sociólogo, etc. El estudio de esta entidad puede ser el lugar en el cual muchas diversidades de análisis y de lenguaje entre las distintas ciencias sociales encuentren una confrontación seria sobre el campo. 
De la propuesta realizada para el estudio de los fenómenos socioeconómicos surge una estrategia de investigación distinta de la tradicional. Las principales líneas de investigación podrían ser: 1) individualizar los sistemas productivos locales, considerando para ello variables cuantitativas y cualitativas; 2) estudiar las diferencias y semejanzas entre ellos, principalmente en el funcionamiento de los mismos, con el fin de clasificar las distintas formas de organización de la producción; 3) redefinir una buena parte del patrimonio conceptual teórico de la economía y la sociología en términos de conexiones específicas entre sistemas locales y vínculos a su evolución, y 4) evidenciar empíricamente si las externalidades cognoscitivas generan un aumento de la productividad del trabajador y su salario ${ }^{33}$.

A continuación, presentamos algunos estudios que intentan determinar los factores de localización más significativos que utilizan las empresas para tomar

\section{TABLA 1}

Factores para empresas de alta tecnología en Estados Unidos

\begin{tabular}{|c|c|c|}
\hline Factor & Región (\%) & Local (\%) \\
\hline Trabajadores no cualificados ........................... & & 52,4 \\
\hline Trabajadores cualificados .............................. & & 88,1 \\
\hline 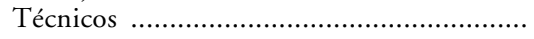 & & 96,1 \\
\hline 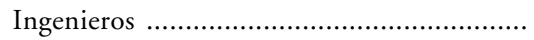 & & 87,3 \\
\hline 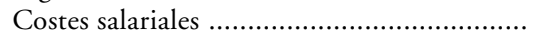 & 72,2 & \\
\hline 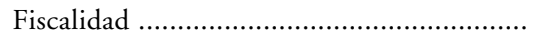 & 67,2 & 85,5 \\
\hline Presencia de una universidad .......................... & 58,7 & \\
\hline 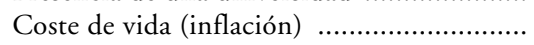 & 58,5 & \\
\hline 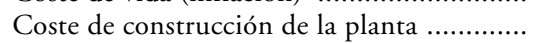 & & 78,8 \\
\hline Coste de transporte de mercancías ............... & 58,4 & 61,1 \\
\hline Coste de transporte de personal .................... & & 76,1 \\
\hline Acceso a los mercados .................................. & 58,1 & \\
\hline 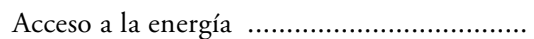 & 41,4 & 45,6 \\
\hline 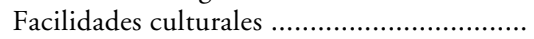 & 36,8 & 61,1 \\
\hline 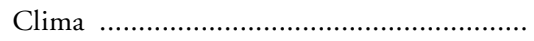 & 35,8 & \\
\hline Acceso a las materia primas ............................ & 27,6 & 36,7 \\
\hline
\end{tabular}

FUENTE: Aydalot (1985).

33 Arrow (1974) establece una relación entre conocimiento y experiencia -learning by doing - . Demuestra que el aprendizaje acumulado permite alcanzar aumentos de productividad. En su modelo, la productividad de una empresa toma la forma de una función creciente dependiente de la inversión acumulada en el conjunto de la industria, siendo el stock de capital un índice de la experiencia acumulada. Para Arrow, el conocimiento es un bien público, ya que todas las empresas pueden acceder a cualquier mejora en el conocimiento que haya podido obtener una empresa. Las innovaciones provocan externalidades o desbordamiento del conocimiento - know-lege spillovers - y explicarían las diferencias en el crecimiento y en la especialización de las distintas localizaciones. 
sus decisiones. Pertenecen a tres ámbitos territoriales (internacional, nacional y local) y tres décadas distintas: Estados Unidos (1969), España (1987) y Campo de Tarragona (1996), respectivamente

\section{TABLA 2}

Factores para empresas industriales españolas

\begin{tabular}{|c|c|}
\hline Factor & Porcentaje \\
\hline 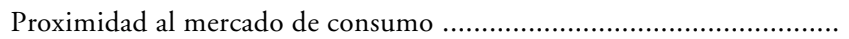 & 22 \\
\hline 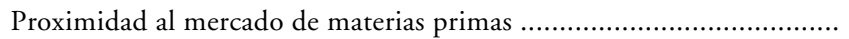 & 20,2 \\
\hline 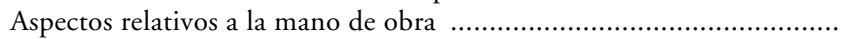 & 19,3 \\
\hline 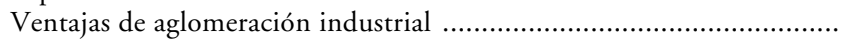 & 11 \\
\hline 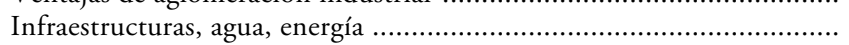 & 11 \\
\hline Facilidades de transportes y comunicaciones & 8,3 \\
\hline 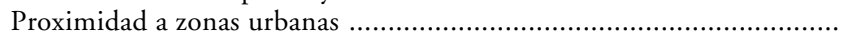 & 5,5 \\
\hline 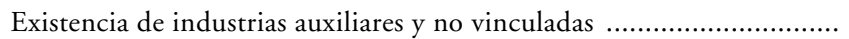 & 1,8 \\
\hline 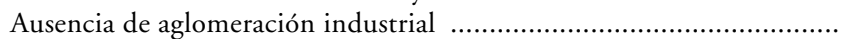 & 0,9 \\
\hline
\end{tabular}

FUENTE: Vázquez Barquero (1987).

TABLA 3

Prioridad en los factores en empresas industriales del Campo de Tarragona

\begin{tabular}{|c|c|c|c|}
\hline Factor & Primero (\%) & Segundo (\%) & Tercero (\%) \\
\hline Existencia de un tejido industrial local especializado ....... & 12 & 8 & 8 \\
\hline 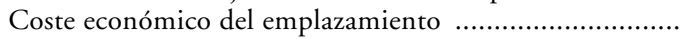 & 16 & 17 & 8 \\
\hline Buena accesibilidad a la zona & 18 & 16 & 21 \\
\hline Infraestructuras disponibles (telecomunicaciones) ........... & 1 & 12 & 9 \\
\hline Nivel de cualificación de la mano de obra local ............... & 4 & 11 & 4 \\
\hline Proximidad a los principales proveedores ........................... & 5 & 12 & 11 \\
\hline 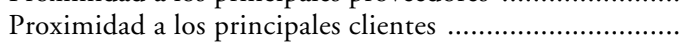 & 26 & 10 & 11 \\
\hline Proximidad a servicios técnicos y profesionales .................. & 1 & 5 & 5 \\
\hline Infraestructuras viarias (carreteras, puertos, etc.) .............. & 10 & 13 & 14 \\
\hline 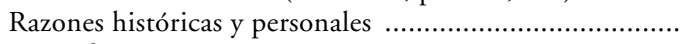 & 25 & 1 & 1 \\
\hline Otros factores & 8 & 0 & 2 \\
\hline
\end{tabular}

FUENTE: Segarra y Oliva (1996).

Puede observarse la evolución reciente sobre cuáles son los factores prioritarios en función de la época y del ámbito territorial de análisis. Así, en la tabla 1, referente a empresas de alta tecnología, se puede ver el escaso papel de los factores tradicionales de localización (mercados, transportes, energía, infra- 
estructura), así como de las economías de aglomeración y los factores relacionados con la polarización industrial. La búsqueda de recursos humanos cualificados domina claramente. Por otro lado, la elevada importancia de factores como el coste de la mano de obra, la fiscalidad local, el clima ciudadano, etc., intervienen negativamente para las grandes ciudades, y mejoran tendencialmente la localización en regiones mejor posicionadas en dichos factores. La cercanía de una universidad es frecuentemente citada por su papel de polo de atracción: como centro de formación de mano de obra cualificada, por el clima favorable que crea, y por el apoyo tecnológico que ofrece a las empresas a través de la investigación especializada. A este respecto, son evidentes las polarizaciones o aglomeraciones industriales, en base a sectores de alta tecnología, que se han creado alrededor de centros universitarios: Silicon Valley en San Francisco, Route 128 en Boston, Orsay en París, Science Park en Cambridge.

En la tabla 2, referente a la situación de las empresas industriales españolas, se observa cómo los principales factores de localización que se utilizan se corresponden con los tradicionales: la proximidad a los mercados de consumo y de materias primas, básicamente. Mientras que en el ámbito local, tabla 3, los factores prioritarios se centran en la proximidad a los clientes, las razones históricas o personales, el coste económico del emplazamiento y la accesibilidad a la zona. Parece, pues, que en la realidad no se están aprovechando las sinergias y el ahorro de costes que pueden surgir de la localización en territorios con mano de obra relativamente cualificada y cercanos a centros universitarios.

Desde la perspectiva de las redes, los recursos humanos pasan a ser también un factor activo y dinámico, esto es, se revalorizan como un elemento de calidad y competitividad, como una pieza clave en la estrategia colectiva. La capacidad de competir de un territorio depende de la calidad de sus recursos humanos al condicionar el nivel tecnológico a utilizar.

Dado el capital humano (sus conocimientos, experiencia, habilidades y capacidades) y la innovación en base a la $\mathrm{I}+\mathrm{D}$, como elementos cruciales para obtener ventajas competitivas en el entorno actual, los sistemas de empresas para no perder competitividad a nivel internacional, máxime cuando la economía cada vez está más interconectada y globalizada, deberán aprovechar eficientemente los recursos humanos y tecnológicos disponibles. Podemos deducir que la eficiencia productiva de la economía no sólo depende de la provisión de factores primarios, es decir, del nivel de capitalización por trabajador ocupado, sino también de la formación inicial de la población ocupada, esto es, de los niveles educativos de la población, y de la curva de aprendizaje de los trabajadores conseguida en el curso de la vida laboral -learning by doing, doing by doing-. Así, dado un determinado estado de la tecnología y una determinada dotación del stock de capital físico por trabajador, la productividad depende en gran manera de la capacidad de los trabajadores -cualificados y no cualificados - para llevar a cabo la tarea que les corresponde en su lugar de 
trabajo. Es por esta razón que el modelo de crecimiento ampliado considera en el capital otras maneras de capital diferente del capital físico. El modelo incluye el conjunto de conocimientos de los trabajadores adquiridos en el sistema educativo y en el lugar de trabajo - learning by doing- y que forman un stock de habilidades y recursos que inciden directamente sobre los niveles de eficiencia de la economía. La consideración del capital humano como una de las fuentes del crecimiento ofrece la posibilidad de considerar la cualificación de los trabajadores y la tecnología incorporada en los bienes de capital físico como factores complementarios. Cada tecnología necesita una formación específica del factor laboral, y las disfunciones entre el nivel tecnológico y la cualificación laboral afectan negativamente los niveles de productividad. Conviene destacar en este sentido las interrelaciones existentes entre las nuevas generaciones de capital y los perfiles formativos de los trabajadores.

\section{Mercados de trabajo locales y valorización del trabajo}

Una manera de definir el mercado de trabajo local es como un ámbito geográfico en el que se cruzan ofertas y demandas de un determinado grupo de agentes. El primer problema que nos plantea esta definición es cómo delimitar este mercado de trabajo. El mercado de trabajo local se asocia a áreas geográficas que no tienen por qué coincidir necesariamente con las unidades administrativas en que se divide tradicionalmente el territorio. Una aproximación al concepto de mercado de trabajo local sería definirlo como: 1) un área delimitada por la distancia máxima en la que un número determinado de trabajadores estaría dispuesto a desplazarse para ocupar una vacante sin que implique necesariamente un cambio de residencia, y 2) el área que delimitan las preferencias de un conjunto de empresas a la hora de contratar sus trabajadores. Sin embargo, esta aproximación en relación a los desplazamientos potenciales de los trabajadores o de las áreas de contratación presenta diversas objeciones: en primer lugar, la dificultad en estimar la distancia máxima a la que los trabajadores están dispuestos a desplazarse; en segundo lugar, cómo delimitar un mercado en el que cada empresa y trabajador tienen su área de búsqueda.

La definición más extendida y utilizada en los países de nuestro entorno es la que delimita los mercados de trabajo locales por fronteras que son cruzadas en el curso de los viajes diarios por la población incluida. Esta definición se basa en el flujo diario de trabajadores entre su residencia y el trabajo. Ahora bien, también se ha de anotar que los patrones de viaje se modifican continuamente por varias razones (por ejemplo, la creación de nuevas zonas residenciales, cambios en la distribución de centros de trabajo, mejoras en las vías de comunicación, medios de transporte públicos, etc.). En todo caso, la definición de mercado de trabajo local a partir de los flujos de trabajadores da lugar 
a que las unidades administrativas no puedan ser consideradas como mercados de trabjo locales ${ }^{34}$.

Para Casado (1996), un mercado laboral local vendría definido por una zona en la que la mayoría de los puestos de trabajo existentes son cubiertos por residentes y que, además, la mayoría de quienes en ella residen se desplazan habitualmente a su trabajo sin necesidad de atravesar sus límites.

La característica fundamental de la organización de los procesos productivos en los sistemas locales de empresas es su carácter flexible; flexibilidad que se confunde con disponibilidad de los trabajadores para soportar alteraciones no planificadas de la carga de trabajo o, también, con poca conflictividad, y es que uno de los factores competitivos de los sistemas locales se basa en la asignación de un precio más bajo a la fuerza de trabajo. Pero la flexibilidad presente en las economías locales no sólo se centra en la reducción comparativa de los costes laborales, sino que también se utiliza el trabajo femenino como forma de dumping laboral, la economía informal, el trabajo a domicilio, la contratación temporal y el alejamiento de los controles sindicales, como una estrategia global para la acumulación de capital.

Los sistemas productivos locales generan mercados internos de trabajo en relación al sistema local, no respecto a la empresa. En este sentido, los mercados locales constituyen unidades apropiadas para estudiar en detalle los procesos de producción y reproducción de la cualificación, tanto desde una perspectiva cuantitativa como social y cultural. Por esta razón, las medidas para favorecer la cualificación o la recualificación de la mano de obra deben articularse necesariamente en el nivel local: la oferta local de mano de obra y la formación, las características de las empresas de la zona, su situación económica coyuntural, las experiencias laborales de la población son elementos clave que se han de tener en cuenta. Porque al interrelacionarse más estrechamente la formación con la productividad de las empresas, su dependencia de la dimensión local de la actividad se hace también más importante. Si la formación ya no es tanto un instrumento para fomentar la disponibilidad general y la movilidad de la población en un mercado de trabajo general, sino especialmente un elemento clave de la productividad de las empresas, ello significa que la interrelación entre formación y empresa debe darse en el contexto de cada unidad local del mercado, y no es suficiente que exista, en general, una relación genérica entre el nivel de formación de la población activa y el nivel tecnológico del sistema productivo. De hecho, si la cualificación es socialmente construida cuando los análisis se remiten a la gran empresa, obviamente, en los sistemas de empresas, señalan Castillo y Santos (1993: 52 y 59), resaltará con mayor claridad. Estos autores destacan tres conclusiones que explicitan de la siguiente manera: 1) la cualificación sólo puede entenderse dentro de, y como resultado de, una determinada división del trabajo; 2) la inteligencia global aplicada a la producción es, generalmen-

34 Véase Casado (1996). 
te, cada vez más alta, ya sea institucionalizada, materializada o encarnada en personas; 3) la evolución de las cualificaciones depende de la distribución o reparto de ese saber entre las personas, trabajadores, trabajadoras, máquinas e instituciones en cada sociedad. Así, "las cualificaciones, las necesidades de formación, esa inencontrable relación cualificación-empleo, depende de cuál sea la división del trabajo dominante en cada obrero colectivo». Por tanto, "si algo especialmente llamativo nos dice la investigación sobre sistemas productivos locales, en relación con la cualificación, es su carácter social y políticamente construido, enraizado en la propia estructura social y en los objetivos que una sociedad determinada se fija a sí misma».

Los mercados de trabajo locales nos plantean, como hipótesis de trabajo, el análisis de las prácticas locales de socialización de los sujetos (empresarios o trabajadores), esto es, las estrategias locales de valorización del trabajo, dando por supuesto que en un contexto local los canales de reclutamiento y búsqueda utilizados por las empresas y trabajadores son informales, es decir, la búsqueda de empleo se realiza a través de la utilización de redes de información no formales. Por otra parte, los sistemas productivos locales tienen un futuro limitado ya que la globalización estimula la centralización y concentración del capital y de los mercados. Las pequeñas y medianas empresas (incluidas las que forman los sistemas locales de empresas, clusters y distritos industriales) están bajo el control tecnológico y comercial de las grandes empresas, por lo que los cambios que genera la reestructuración de regiones están condicionados por el proceso de globalización y, por tanto, por la estrategia de las grandes empresas multinacionales ${ }^{35}$.

En definitiva, el capitalismo global, que dicta sus normas en la economía mundial, se las ha ingeniado para crear una ideología en torno a una nueva ética del trabajo ${ }^{36}$ en que los recursos humanos, es decir, los recursos en cualificación, son esenciales para el desarrollo y la utilización del capital y de la tecnología ${ }^{37}$. El éxito competitivo exige, por un lado, la vuelta de la fuerza de trabajo cualificada como elemento consciente y vital en la totalidad del proceso productivo; por otro, sigue la identificación con el trabajo que permita incrementar el rendimiento, reducir el absentismo y la conflictividad laboral $^{38}$. Sin embargo, el trabajo sólo puede comprenderse en su verdad obje-

35 Véanse Harrison (1994), Veltz (1999), Amin y Rabnis (1991), Castillo (1999; 1991; 1989).

36 Para una crítica a esta nueva ética del trabajo, véase Gorz (1995).

37 El Banco Mundial, en el año 1995, estimaba que el capital humano constituía un $67 \%$ de la riqueza de los países desarrollados, y afirmaba que las conexiones transfronterizas entre las universidades y los centros de investigación de las grandes ciudades del mundo dentro de un mercado único del conocimiento aparecían como una punta de lanza para afrontar con garantías el siglo XXI.

38 Como señala Veltz (1999: 165), la llamada a la «implicación de los obreros y de los asalariados en general en la calidad y en la cooperación productiva, tiene más posibilidades de ser entendida en una sociedad solidaria y abierta que en una sociedad de castas y de desigualdades». 
tivamente doble. Verdad objetiva del trabajo como explotación, y verdad subjetiva como inversión en el trabajo, que conduce a encontrar en él un beneficio intrínseco, irreductible a la mera ganancia en dinero, y que «forma parte de las condiciones reales de la realización del trabajo, así como de la explotación» (Bourdieu, 1999: 266). Por tanto, las disposiciones de los trabajadores, esto es, lo más subjetivo y lo más personal, constituyen parte integrante de la realidad de cuyo análisis se ha de dar cuenta. Y es que la propensión «a invertir en el trabajo y desconocer su verdad objetiva es, sin duda, tanto mayor cuanto más completamente sintoniza las expectativas colectivas inscritas en el puesto de trabajo con las disposiciones de sus ocupantes" (Bourdieu, 1999: 268$)^{39}$.

39 En opinión de Bourdieu (1998), la ideología neoliberal constituye un programa de destrucción metódica de lo colectivo, imponiendo, en todas partes, en las altas esferas de la economía y del Estado, o en el seno de las empresas, una especie de darwinismo moral que, con el culto al ganador, instaura como norma la práctica de la lucha de todos contra todos y el cinismo. 


\section{BIBLIOGRAFÍA}

AlONSO, L. E. (1999): «El discurso de la globalización y la nueva desigualdad regional», Estudios Regionales, núm. 54.

Amin, S. (1995): «Les conditions globales d'un développement durable», en Alternatives Sud, vol. II, París.

- (1997): Los desafios de la mundialización, Siglo XXI, Buenos Aires.

Amin, A., y RoBINS, K. (1991): «Distritos industriales y desarrollo regional: límites y posibilidades», Sociología del Trabajo, número extraordinario.

Arrow, K. J. (1974): Limits of Organization, Norton, Nueva York.

AYDAlOT, P. (1985): Economia régionale et urbaine, Economica, París.

- (1986): Milieux Innovateurs in Europe, Gremi, París.

Bagnasco, A. (1977): Tre Italie: La problemática territoriale dello sviluppo italiano, Il Molino, Bolonia.

Becattini, G. (1978): "Del "sector industrial" al "districte industrial". Algunes consideracions sobre la unitat de recerca de l'economia industrial", Revista Econòmica de Catalunya, vol. gen.-abr. 1986, núm. 1.

- (1979): «Dal Settore Industriale al Distretto Industriale. Alcune considerazioni sull'unità di indagine dell economia industriale», Revista di Economia e Politica Industriale, núm. 1.

- (ed.) (1987): Mercato e foze locali. Il distreto industriale, Il Mulino, Bologna.

- (1990): "The Marshallian industrial district as a socioeconomic notion", en F. PYKE, G. Becattini y W. Sengenberger, Industrial Districts and Interfirm Cooperation in Italy, International Institute for Labor Studies, Génova.

Becattini, G., y Rullani, E. (1994): «Sistema locale e mercato globale», en G. Becattini y S. Vacca (eds.).

BECK, U. (1997): «La reinvención de la política: hacia una teoría de la modernización reflexiva», en U. Beck, A. Giddens y S. Lash, Modernización reflexiva. Política, tradición y estética en el orden social moderno, Alianza, Madrid.

Best, M. (1990): The New Competition: Institutions of Industrial Restructuring, Cambridge Polity Press, Cambridge.

BiAnCHI, P. (1990): «Niveles de política y naturaleza de la competencia post-fordista», Revista Económica de Catalunya, núm. 14.

BoISIER, S. (1998): «Las regiones como espacios socialmente construidos», Revista de la CEPAL, núm. 35.

Bourdieu, P. (1998): «L'essance du néoliberalisme», Le Monde Diplomatique, marzo.

- (1999): Contrafuegos. Reflexiones para servir a la resistencia contra la invasión neoliberal, Anagrama, Barcelona.

Bramanti, A., y Miglierina, C. (1995): «Alle radici della crescita regionale: fattori, fenomeni, agenti», L'industria, vol. XVI, núm. 1.

BRusCo, S. (1982): "The Emilian Model: Productive Decentralisation and Social Integration», Cambridge Journal Economics, vol. 6.

- (1986): "Small Firms and Industrial Districts: The Experience of Italy», en D. Keeble y E. Weber (eds.), New Firms and Regional Development in Europe, Croom Helm, Londres.

Callejón, M., y Costa Campí, M. T. (1995): «Economías externas y localización de las actividades industriales», Economía Industrial, núm. 305.

CASAdo, J. M. (1996): Mercados laborales locales, Documento de trabajo, núm. 9603, Universitat d'Alacant.

CASTELls, M. (1997): La era de la información. Economía, sociedad y cultura, vol. 1: La Sociedad Red, Alianza Editorial, Madrid.

Castells, M., y Hall, P. (1994): Las tecnópolis del mundo. La formación de los complejos industriales del siglo XXI, Alianza Editorial, Madrid. 
Castillo, J. J. (1989): La división del trabajo entre empresas, Ministerio de Trabajo, Madrid.

- (1991a): Informatización, trabajo y empleo en las pequeñas empresas españolas, Ministerio de Trabajo y Seguridad Social, Madrid.

- (1991b): «Diseño del trabajo y cualificación de los trabajadores en una fábrica de motores», en J. J. Castillo (comp.), La automatización y el futuro del trabajo, Ministerio de Trabajo y Seguridad Social, Madrid.

- (1999): El trabajo del futuro, Editorial Complutense, Madrid.

Castillo, J. J., y SANTOS, M. (1993): «La cualificación del trabajo y los distritos industriales», Economía y Sociología del Trabajo, 21-22.

Cicıотті, E. (1993): Competitività e territorio. L'economia regionale nei paesi industrializzati, La Nuova Italia Scientifica, Roma.

FURIÓ, E. (1996): Evolución y cambio en la economía regional, Ariel, Barcelona.

Glaeser, E.; Kallal, H.; Scheinkman, J., y Shleifer, A. (1992): "Growth in Cities», Journal of Political Economy, 100, 6.

GorZ, A. (1995): La metamorfosis del trabajo, Sistema, Madrid.

- (1998): Miserias del presente, riqueza de lo posible, Paidós, Buenos Aires.

HARrison, B. (1994): La empresa que viene. La evolución del poder empresarial en la era de la flexibilidad, Paidós, Barcelona.

Henderson, V.; Kuncoro, A., y Turner, M. (1995): «Industrial Development in Cities», Journal of Political Economy, vol. 103, núm. 51.

JACOBS, J. (1984): Las ciudades y la riqueza de las naciones, Ed. Ariel, Barcelona.

Krugman, P. (1991): «Increasing Returns and Economic Geography», Journal of Political Economy, núm. 99.

- (1997): Desarrollo, geografía y teoría económica, Bosch Editor, Barcelona.

Marshall, A. (1920): Principles of Economics eight edition, McMillan, Londres.

- (1927): Industry and Trade, McMillan, Londres.

Mendras, H. (1999): Sociología de Europa occidental, Alianza Editorial, Madrid.

Myrdal, G. (1957): Teoría Económica y Regiones Subdesarrolladas, Fondo de Cultura Económica, México.

PIORE, M. J., y SABEL, Ch. (1990): La segunda ruptura industrial, Alianza Editorial, Madrid.

Porter, M. E. (1990): La ventaja competitiva de las naciones, Plaza \& Janés, Barcelona.

Richardson, G. B. (1969): Elements of Regional Economics, Penguin Books, Harmondsworth.

SaXenian, A. (1994): Regional Advantage, Cultural and Competition in Silicon Valley and Route 128, Harvard University Press, Cambridge (MA).

Segarra, A., y Oliva, M. (dirs.) (1996): Indústria i estratègies empresarials al Camp de Tarragona, Autoritat Portuària de Tarragona y Universitat Rovira i Virgili, Tarragona.

SENNET, R. (2000): La corrosión del carácter. Las consecuencias personales del trabajo en el nuevo capitalismo, Anagrama, Barcelona.

VAlDAliso, J. M.a, y López, S. (2000): Historia económica de la empresa, Crítica, Barcelona.

VÁzquez Barquero, A. (1987): «Local Development and Regional State in Spain», Papers of the Regional Science Association, vol. 61.

- (1993): Política económica local, Pirámide, Madrid.

- (1998): "La política de desarrollo económico local en Europa», en F. Rodríguez (ed.), Manual de desarrollo local, TREA, Gijón.

- (1999): La Teoría del Desarrollo Endógeno, Pirámide, Madrid.

Veltz, P. (1999): Mundialización, ciudades y territorios, Ariel, Barcelona. 


\begin{abstract}
This article analyses how the company influences the region in which it carries out its activities. The authors claim that the company could not exist outside the social, cultural, politicas and economic fabric of society. They describe where the industry is located, identify the dynamic economies, as Marshall called them, as well as regions where productive synergies have been generated and, in recent decades, studied by economist and sociologists. The article also describes the dynamics of clusters, industrial districts and, finally, some of the more important aspects of local labour markets.
\end{abstract}

